American Journal of Public administration
(ISSN:2641-4597)

\title{
State Eviction Bans: A Policy Response to COVID-19
}

\author{
Susan E. Baer, Ph.D. ${ }^{{ }^{*}}$, Victor Ferreros, Ph.D. ${ }^{1}$
}

${ }^{1}$ Walden University, Contributing Faculty Member, School of Public Policy and Administration.

\begin{abstract}
The COVID-19 pandemic has shined a light on the importance ${ }^{*}$ Correspondence to Author: of housing as a social determinant of health. To prevent millions Susan E. Baer, Ph.D. of American renters from being evicted from their homes during Walden University, Contributing the COVID-19 pandemic and potentially becoming homeless, Faculty Member, School of Public the Centers for Disease Control and Prevention (CDC) issued Policy and Administration. a temporary eviction ban order on September 4, 2020 that has currently been extended through June 30, 2021. This paper How to cite this article: examines the rationale for the CDC temporary eviction ban Susan E. Baer, Victor Ferreros. order from a public health perspective. It then uses statistical State Eviction Bans: A Policy Retechniques to explore the relationship between political and sponse to COVID-19. American demographic variables and temporary eviction bans enacted in Journal of Public administration, individual states during the pandemic. Results show a statistically $2021 ; 3: 11$

significant relationship between political party control of the state legislature and temporary state eviction bans which suggests that partisanship has largely driven the use of temporary eviction bans as a policy response to COVID-19 at the state level.

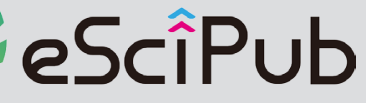

eSciPub LLC, Houston, TX USA.

Website: https://escipub.com/

Keywords: Eviction ban; Eviction moratorium; Eviction; COVID19; Homelessness; Partisanship
\end{abstract}




\section{Introduction}

The Centers for Disease Control and Prevention (CDC) issued an order temporarily halting residential evictions in the United States effective September 4, 2020 through December 31,2020 , because an eviction moratorium can be an effective policy to prevent the spread of COVID-19 during a pandemic. The CDC has extended this order three times through January 31,2021 , March 31, 2021, and currently through June 30,2021 . This order intends to protect an estimated 43 million renters in the United States from being evicted and potentially becoming homeless. States can also impose additional eviction ban policies. The Coronavirus Aid, Relief, and Economic Security (CARES) Act previously provided a 120-day moratorium on residential evictions, but the CARES Act eviction moratorium expired on July 24, 2020. This paper first examines why officials implemented temporary eviction bans in the United States during the COVID-19 pandemic from a public health perspective, and it then uses statistical techniques to explore the relationship between political and demographic variables and the temporary eviction ban policies enacted in individual states during the COVID-19 pandemic.

\section{Rationale for the CDC Temporary Eviction Ban}

As of April 15, 2021, 561,356 people have died in the United States as a result of COVID-19 (Centers for Disease Control and Prevention [CDC], 2021b). Infectious disease pandemics disproportionately impact people experiencing poverty, marginalization, stigmatization, and discrimination. In the context of the COVID-19 pandemic, this disparity is particularly relevant for people who experience homelessness (Perri et al., 2020).

Eviction bans enable state and local authorities to more easily implement stay-at-home and social distancing orders to lessen the transmission of COVID-19 in their communities. Eviction bans help to protect public health, because people who experience homelessness as a result of a forced move become more likely to move into shared housing or congregate settings which then places them at higher risk for contracting COVID-19. Eviction bans also allow self-isolation by people who become ill or who are at risk for severe disease from COVID19 as a result of an underlying medical condition (Centers for Disease Control and Prevention [CDC], 2021).

Risk of COVID-19 Transmission Among People Who Experience Homelessness

According to the CDC, many evicted renters move into shared housing or other congregate settings. Specifically, a sizeable 32 percent of renters report that they would move in with friends or family members upon being evicted. Household contacts are estimated to be 6 times more likely to become infected with COVID-19 than other close contacts. Preliminary data indicate that evictions substantially contribute to COVID-19 transmission. Over 433,000 cases of COVID-19 in the United States and over 10,000 deaths could be attributed to lifting state eviction bans (CDC, 2021).

Shared housing includes a wide array of settings including homeless shelters and domestic violence and abuse shelters and, thus, is not limited to friends or family. In addition, some evicted individuals may initially stay with friends or family but later seek homeless services. Among individuals who entered shelters in 2017 in the United States, 27 percent stayed with friends or family before entering the shelters (CDC, 2021).

Special considerations exist for shelters, because residents often gather closely or use shared facilities there such as kitchen and laundry facilities. As a result, maintaining social distance in shelters presents a challenge. The CDC recommends that shelters give new residents a clean mask, keep them isolated from others, screen them for COVID-19 symptoms at entry, or arrange for medical evaluation as needed. An influx of new residents at shelters due to having been evicted could overwhelm 
staff and potentially lead to new COVID-19 exposures (CDC, 2021).

In order to reduce the transmission of COVID19 , organizations that provide services to people experiencing homelessness must create conditions that allow physical distancing. One strategy to do this involves opening new shelter spaces and increasing spacing between beds. Moving people who experience homelessness into hotels and motels serves as another strategy to enable physical distancing, and this strategy has been used in locations including Los Angeles and New York City, among others (Perri et al., 2020; Stewart, 2020).

These efforts require commitments of additional funding and human resources which both prove difficult in the context of the COVID-19 pandemic. Temporary and permanent business closures that occurred during the pandemic have resulted in drastically lower financial and material donations to nonprofit organizations that provide services to people who experience homelessness. Because communities have practiced sheltering in place and social distancing in order to reduce the spread of COVID-19, the number of persons who are able to volunteer for nonprofit organizations that provide homelessness services has also been sharply reduced (Ha et al., 2021).

Data provide support that people experiencing homelessness are at high risk for contracting COVID-19, and that homeless shelters have experienced extensive outbreaks of COVID-19. Testing at a homeless shelter in San Francisco, California identified 101 COVID-19 cases or 67 percent of those tested (CDC, 2021). Among 408 people experiencing homelessness and living in shelters in Boston, Massachusetts, 36 percent tested positive for COVID-19 (Perri et al., 2020).

Homelessness and the Risk of Severe Disease from COVID-19

The population of evicted individuals who become homeless include many who are predisposed to developing severe disease from COVID-19. A relationship exists between eviction and health problems (Desmond \& Kimbro, 2015; Desmond, 2016) including hypertension which has been associated with more severe cases of COVID-19 (CDC, 2021). In addition, people experiencing homelessness often have underlying conditions including heart disease, respiratory conditions, liver disease, high rates of smoking, and other factors such as poor nutrition that increase their risk of developing severe disease from COVID-19 (Alarcon \& Khan, 2021; Ha et al., 2021; Perri et al., 2020). Among COVID-19 patients, homelessness is associated with an increased likelihood of hospitalization (CDC, 2021).

In effect, evictions can increase the spread of COVID-19 as they may force people to move into shared housing settings with friends or family or into congregate settings such as homeless shelters. Evictions then prove especially problematic to people who subsequently experience homelessness, because these individuals are more likely to develop severe disease from COVID-19 (CDC, 2021). Organizations that provide homelessness services identify lack of timely and ongoing public health communications, difficulty maintaining effective infection control measures, lack of adequate personal protective equipment, and challenges to achieving effective client screening as particularly problematic during the COVID-19 pan- demic (Perri et al., 2020). In order to both reduce the transmission of COVID-19 and reduce the spread of severe disease from COVID-19, the CDC issued a temporary eviction ban order.

\section{The Role of States}

States play a key role in shaping U.S. health policy (Conlan \& Posner, 2011), and they have historically been on the frontline of efforts to control infectious disease (Gusmano et al., 2020). In terms of the COVID-19 pandemic, the CDC order does not prevent state or local officials from issuing additional requirements that are more restrictive and provide greater public health protection than the requirements given in the order. In addition, the CDC order 
does not apply to any state or locality with an eviction ban that provides the same or greater level of public health protection than the requirements given in the order (CDC, 2021).

\section{Methods}

Based on an examination of temporary state eviction ban data found on the Nolo legal website on December 26, 2020, the authors analyzed state eviction bans enacted during the COVID-19 pandemic that lasted at least as long as December 31, 2020 which is the date the original CDC eviction ban order ended. The CDC subsequently extended the order three times, and it is currently in place through June 30,2021 . Because the duration of both temporary state eviction bans and the CDC temporary eviction ban are subject to change, the authors selected the specific end date of December 31, 2020 for this paper's analysis.

Aggregate cross sectional data for selected political and demographic variables for the fifty states and the District of Columbia were examined relative to state eviction bans. Descriptive data were summarized and analyzed using standard univariate techniques and cross tabulations of relevant variables. Correlations were calculated for all relevant variables and partial correlations were calculated for certain combinations of variables prior to developing binary outcome models specifying temporary state eviction bans as a function of subsets of political and demographic variables.

Binary outcome models were fitted using binary logit and probit functions as the dependent variable of temporary state eviction bans was measured in dichotomous fashion. States were coded as 1 if a statewide temporary eviction ban was implemented or 0 if there was no ban. Logit and probit regressions appeared to be the only feasible way to measure the relative effects of multiple independent variables. A limitation is the nature of the data and the sample size of 50 states. This required fitting a parsimonious set of independent variables to the binary outcome models.

\section{Results}

\section{Political Variables}

Temporary eviction bans that extended at least as long as December 31, 2020 were implemented during the COVID-19 pandemic in 17 out of the 50 states as well as the District of Columbia either by executive order or legislative action. In the case of New Mexico, the state Supreme Court placed a temporary ban on evictions. In addition to the District of Columbia, the states that implemented temporary eviction bans during the pandemic included California, Colorado, Connecticut, Delaware, Hawaii, Illinois, Kansas, Maryland, Minnesota, Nevada, New Jersey, New Mexico, New York, Oregon, Vermont, Virginia, and Washington.

Temporary state eviction bans (EB) are measured as a binary variable. Eviction bans were cross tabulated against three political variables: political party control of the state legislature (PCSL), the governor's political party identification (GPP), and the winner's political party identification in the 2020 presidential election (PER). The following 2X2 contingency tables show that political party identification was significantly correlated with the enactment of temporary eviction bans across the states.

Table 1 EB PCSL Crosstabulation

EB * PCSL Crosstabulation

\begin{tabular}{ccc|c|c} 
& \multicolumn{5}{c}{ Count } \\
& & \multicolumn{2}{c}{ PCSL } & \\
& & 0 & 1 & Total \\
\hline EB & 0 & 30 & 3 & 33 \\
\cline { 2 - 5 } & 1 & 1 & 17 & 18 \\
\hline \multicolumn{2}{c}{ Total } & 31 & 20 & 51 \\
\hline
\end{tabular}


The Phi coefficient of association between political party control of the state legislature and eviction bans was .835 and statistically significant. Of the 50 states as well as the
District of Columbia, 20 state legislatures were controlled by Democrats and only three of these including Maine, Massachusetts, and Rhode Island did not have an eviction ban.

Table 2 EB GPP Crosstabulation

\section{EB * GPP Crosstabulation}

Count

\begin{tabular}{l|r|r|r|r} 
& \multicolumn{5}{c}{ GPP } & \multicolumn{1}{c}{} \\
& & \multicolumn{1}{c}{0} & 1 & \multicolumn{1}{c}{ Total } \\
\hline \multirow{2}{*}{ EB } & 0 & 24 & 9 & 33 \\
\cline { 2 - 6 } & 1 & 2 & 16 & 18 \\
\hline \multirow{2}{*}{ Total } & & 26 & 25 & 51 \\
\hline
\end{tabular}

Eviction bans were also significantly associated with the Governor's political party identification. Of the 25 states with Democratic governors, only nine did not have eviction bans. In contrast, only
2 states with Republican governors, Maryland and Vermont, had eviction bans. The coefficient of association was .589 and statistically significant.

Table 3 EB PER Crosstabulation

\section{EB * PER Crosstabulation}

\begin{tabular}{|c|c|c|c|c|}
\hline \multicolumn{5}{|c|}{ Count } \\
\hline & & \multicolumn{2}{|c|}{ PER } & \multirow[b]{2}{*}{ Total } \\
\hline & & 0 & 1 & \\
\hline \multirow[t]{2}{*}{ EB } & 0 & 24 & 9 & 33 \\
\hline & 1 & 1 & 17 & 18 \\
\hline Total & & 25 & 26 & 51 \\
\hline
\end{tabular}

State eviction bans were also tabulated against 2020 presidential election results by political party. Of the 26 states won by Biden, 17 had eviction bans and nine did not. The coefficient of association was .642 and statistically significant. Political and Demographic Variables

In addition to the political variables, demographic variables that would reasonably relate to temporary state eviction bans were also examined. Relevant indicators included state poverty rate (POVP), state unemployment rate (UNEMP), state homelessness rate per 10000 population (HLESS), percentage of renter homes per state (RENTP), state cost of living $(\mathrm{COL})$, and rent as a percentage of median family income in state (RP). Certain demographic variables such as the ethnic percentages of state population were also included: percentage white (WHIP), percentage African American (AAP), percentage Hispanic (HLP), and percentage Asian (ASNP). A correlation matrix between the variables is displayed as Table 4.

All of the political and demographic variables displayed statistically significant correlations with temporary state eviction bans. The demographic variables all were significant, and most were in the expected direction. The highest correlations showed that homelessness rate and cost of living were the highest at .448 and 
.542 respectively. Poverty rate at -.281 showed a negative correlation with eviction bans. The unemployment coefficient was slightly larger at .375 and in the expected direction. Renter homes as a percentage of total homes and rent as a percentage of median family income were at .374 and .387 respectively. Distributions of the variables were examined to determine the presence of outliers potentially affecting the size of the correlations.

Table 4 Correlation Matrix

\begin{tabular}{|c|c|c|c|c|c|c|c|c|c|c|c|c|c|c|c|}
\hline \multicolumn{16}{|c|}{ Correlations } \\
\hline & & EB & PCSL & GPP & PER & POVP & UNEMP & HLESS & RENTP & $\mathrm{COL}$ & $\mathrm{RP}$ & WHIP & AAP & HLP & ASNP \\
\hline \multirow[t]{2}{*}{ EB } & Pearson Correlation & -- & & & & & & & & & & & & & \\
\hline & $\mathrm{N}$ & 51 & & & & & & & & & & & & & \\
\hline \multirow[t]{3}{*}{ PCSL } & Pearson Correlation & $.835^{* *}$ & -- & & & & & & & & & & & & \\
\hline & Sig. (1-tailed) & .000 & & & & & & & & & & & & & \\
\hline & $\mathrm{N}$ & 51 & 51 & & & & & & & & & & & & \\
\hline \multirow[t]{3}{*}{ GPP } & Pearson Correlation & $.589^{* *}$ & $.578^{\prime \prime}$ & -- & & & & & & & & & & & \\
\hline & Sig. (1-tailed) & .000 & .000 & & & & & & & & & & & & \\
\hline & $\mathrm{N}$ & 51 & 51 & 51 & & & & & & & & & & & \\
\hline \multirow[t]{3}{*}{ PER } & Pearson Correlation & $.642^{\mathrm{Nn}}$ & $.788^{\prime \prime}$ & $.569^{\prime \prime}$ & - & & & & & & & & & & \\
\hline & Sig. (1-tailed) & .000 & .000 & .000 & & & & & & & & & & & \\
\hline & $\mathrm{N}$ & 51 & 51 & 51 & 51 & & & & & & & & & & \\
\hline \multirow[t]{3}{*}{ POVP } & Pearson Correlation & $-.281^{*}$ & $-.322^{x}$ & -.054 & $-.349^{\prime \prime}$ & -- & & & & & & & & & \\
\hline & Sig. (1-tailed) & .023 & .011 & .354 & .006 & & & & & & & & & & \\
\hline & $\mathrm{N}$ & 51 & 51 & 51 & 51 & 51 & & & & & & & & & \\
\hline \multirow[t]{3}{*}{ UNEMP } & Pearson Correlation & $.375^{\mathrm{N}}$ & $.395^{\mathrm{N}}$ & $.433^{\mathrm{Nx}}$ & $.369^{\mathrm{Nx}}$ & .156 & -- & & & & & & & & \\
\hline & Sig. (1-tailed) & .003 & .002 & .001 & .004 & .138 & & & & & & & & & \\
\hline & $\mathrm{N}$ & 51 & 51 & 51 & 51 & 51 & 51 & & & & & & & & \\
\hline \multirow[t]{3}{*}{ HLESS } & Pearson Correlation & $.448^{\mathrm{kn}}$ & $.477^{\mathrm{N}}$ & $.304^{x}$ & $.381^{* x}$ & -.040 & $.369^{\mathrm{N}}$ & - & & & & & & & \\
\hline & Sig. (1-tailed) & .000 & .000 & .015 & .003 & .391 & .004 & & & & & & & & \\
\hline & $\mathrm{N}$ & 51 & 51 & 51 & 51 & 51 & 51 & 51 & & & & & & & \\
\hline \multirow[t]{3}{*}{ RENTP } & Pearson Correlation & $.374^{n *}$ & $.396^{\mathrm{N}}$ & $.300^{*}$ & $.304^{*}$ & .057 & $.587^{\mathrm{kn}}$ & $.841^{\prime \prime}$ & - & & & & & & \\
\hline & Sig. (1-tailed) & .003 & .002 & .016 & .015 & .345 & .000 & .000 & & & & & & & \\
\hline & $\mathrm{N}$ & 51 & 51 & 51 & 51 & 51 & 51 & 51 & 51 & & & & & & \\
\hline \multirow[t]{3}{*}{$\mathrm{COL}$} & Pearson Correlation & $.542^{\star \pi}$ & $.641^{* *}$ & $.416^{* \pi}$ & $.540^{* \pi}$ & $-.336^{\star \star}$ & $.519^{* \pi}$ & $.785^{\star \star}$ & $.667^{\star \pi}$ & - & & & & & \\
\hline & Sig. (1-tailed) & .000 & .000 & .001 & .000 & .008 & .000 & .000 & .000 & & & & & & \\
\hline & $\mathrm{N}$ & 51 & 51 & 51 & 51 & 51 & 51 & 51 & 51 & 51 & & & & & \\
\hline \multirow[t]{3}{*}{ RP } & Pearson Correlation & $.387^{\mathrm{N}}$ & $.378^{\prime \prime}$ & $.235^{*}$ & $.337^{\mathrm{N}}$ & .190 & $.618^{* \pi}$ & $.480^{\mathrm{Nx}}$ & $.571^{\star *}$ & $.527^{\star *}$ & -- & & & & \\
\hline & Sig. (1-tailed) & .003 & .003 & .049 & .008 & .091 & .000 & .000 & .000 & .000 & & & & & \\
\hline & $\mathrm{N}$ & 51 & 51 & 51 & 51 & 51 & 51 & 51 & 51 & 51 & 51 & & & & \\
\hline \multirow[t]{3}{*}{ WHIP } & Pearson Correlation & $-.431^{x \times}$ & $-.355^{\mathrm{N}}$ & $-.246^{\star}$ & $-.294^{\star}$ & -.229 & $-.726^{\star \star}$ & $-.475^{\star \pi}$ & $-.653^{\star \star}$ & $-.502^{n \star}$ & $-.754^{\star \star}$ & - & & & \\
\hline & Sig. (1-tailed) & .001 & .005 & .041 & .018 & .053 & .000 & .000 & .000 & .000 & .000 & & & & \\
\hline & $\mathrm{N}$ & 51 & 51 & 51 & 51 & 51 & 51 & 51 & 51 & 51 & 51 & 51 & & & \\
\hline \multirow[t]{3}{*}{ AAP } & Pearson Correlation & .039 & -.017 & .007 & -.014 & $.437^{* \pi}$ & .170 & .192 & $.292^{*}$ & .014 & $.298^{*}$ & $-.462^{\star x}$ & - & & \\
\hline & Sig. (1-tailed) & .393 & .454 & .481 & .462 & .001 & .117 & .088 & .019 & .460 & .017 & .000 & & & \\
\hline & $\mathrm{N}$ & 51 & 51 & 51 & 51 & 51 & 51 & 51 & 51 & 51 & 51 & 51 & 51 & & \\
\hline \multirow[t]{3}{*}{ HLP } & Pearson Correlation & $.370^{n \pi}$ & $.331^{\prime *}$ & .210 & $.295^{*}$ & .119 & $.543^{\star n}$ & .194 & $.396^{\star \pi}$ & .151 & $.529^{\star \star}$ & $-.625^{\mathrm{N}}$ & -.128 & -- & \\
\hline & Sig. (1-tailed) & .004 & .009 & .069 & .018 & .202 & .000 & .087 & .002 & .144 & .000 & .000 & .184 & & \\
\hline & $\mathrm{N}$ & 51 & 51 & 51 & 51 & 51 & 51 & 51 & 51 & 51 & 51 & 51 & 51 & 51 & \\
\hline \multirow[t]{3}{*}{ ASNP } & Pearson Correlation & $.444^{n *}$ & $.433^{\mathrm{k}}$ & $.305^{*}$ & $.377^{* *}$ & $-.286^{*}$ & $.553^{\prime \prime}$ & $.437^{* *}$ & $.445^{* \pi}$ & $.790^{* *}$ & $.517^{\mathrm{N}}$ & $-.594^{\mathrm{N}}$ & -.090 & .210 & -- \\
\hline & Sig. (1-tailed) & .001 & .001 & .015 & .003 & .021 & .000 & .001 & .001 & .000 & .000 & .000 & .265 & .069 & \\
\hline & $\mathrm{N}$ & 51 & 51 & 51 & 51 & 51 & 51 & 51 & 51 & 51 & 51 & 51 & 51 & 51 & 51 \\
\hline
\end{tabular}

An examination of the distributions of the homelessness and cost of living variables showed that a significant outlier was the District of Columbia in terms of homelessness and Hawaii in terms of the cost of living. The distributions of renters as a percentage of all homes and rent as a percentage of median family income showed that the District of Columbia and the state of Florida respectively were notable outliers. As a result, both observations were omitted and correlations were recalculated for the demographic variables as presented in Table 5 . In addition the variables for homelessness, renter homes as a 
percentage of all homes, and rent as a percentage of median family income were log transformed based on Shapiro Wilks tests of normality. The correlations continued to be significant even with the deletion of the two outliers from the analysis.

In Table 4, the statewide percentages of whites, Hispanics, and Asian Americans showed significant correlations with temporary state eviction bans while African Americans showed no relationship. The white percentage was also highly negatively correlated with eviction bans.
An examination of the distributions of the variables confirmed the existence of outliers with DC and Mississippi in the case of African Americans, California and New Mexico in the case of Hispanics, and Hawaii and California in the case of Asian Americans. The recalculated correlation matrix in Table 5 did not adjust for these outliers except for the District of Columbia. The correlations continued to exhibit significance in the same direction, again with the exception of African Americans.

Table 5 Adjusted Correlation Matrix

\begin{tabular}{|c|c|c|c|c|c|c|c|c|c|c|}
\hline & $\mathrm{EB}$ & UNEMP & POVP & LHLESS & LRENTP & LRP & WHIP & AAP & HLP & ASNP \\
\hline $\mathrm{EB}$ & 1.0000 & & & & & & & & & \\
\hline UNEMP & 0.3668 & 1.0000 & & & & & & & & \\
\hline POVP & -0.3088 & 0.1438 & 1.0000 & & & & & & & \\
\hline LHLESS & 0.4607 & 0.3723 & -0.2743 & 1.0000 & & & & & & \\
\hline LRENTP & 0.3172 & 0.6591 & -0.0116 & 0.6281 & 1.0000 & & & & & \\
\hline LRP & 0.4458 & 0.6529 & 0.1979 & 0.5548 & 0.6414 & 1.0000 & & & & \\
\hline WHIP & -0.4184 & -0.7330 & -0.2039 & -0.3165 & -0.6290 & -0.7655 & 1.0000 & & & \\
\hline AAP & -0.0567 & 0.1290 & 0.4410 & -0.4261 & -0.0077 & 0.2895 & -0.3717 & 1.0000 & & \\
\hline HLP & 0.4069 & 0.5523 & 0.1181 & 0.3537 & 0.5201 & 0.5041 & -0.6529 & -0.1565 & 1.0000 & \\
\hline ASNP & 0.4527 & 0.5593 & -0.2859 & 0.5787 & 0.5569 & 0.5543 & -0.6357 & -0.0967 & 0.2205 & 1.0000 \\
\hline
\end{tabular}

The lack of correlation with respect to African Americans may be explained by the level of aggregation of the data. The variable could be related if city level data were used or if survey data at the individual level were examined. The use of aggregate data for inferences regarding individual characteristics or the behavior of ethnic groups is illustrative of the ecological fallacy problem. The absence of correlation between the African American percentage and temporary state eviction bans may be due to this type of aggregation bias. Because of a concern for aggregation bias, these variables were excluded from the binary outcome models.

The intent to develop alternative binary outcome models of temporary state eviction bans revolved around determining which of the variables were most important in explaining the occurence of these bans. Furthermore, care had to be exercised in selecting the most meaningful and parsimonious subset of variables given the limitation of small sample size and the statistical assumptions of logit and probit regression. With respect to the demographic variables, interest revolved around the relative importance of poverty, unemployment, and homelessness. Cost of living was highly correlated with all demographic variables, raising the potential for multicollinearity. Consequently the cost of living variable was excluded from the binary outcome models. Partial correlations were also calculated for the remaining demographic variables to get an idea of relative importance. Unemployment rate and the homelessness rate continued to exhibit significance when controlling for each other and all other demographic variables.

\section{Binary Outcome Models}

Binary outcome models were fitted to the data, and alternative combinations of variables were evaluated to determine the most meaningful subset of variables that explained temporary state eviction bans. Care was exercised to avoid issues of multicollinearity and the inclusion of too many predictors given the small sample size. 
Omission of the aggregate racial characteristics of the population from the binary outcome models enabled winnowing the number of predictors to a smaller, more manageable number. These characteristics are better studied in more detailed levels of aggregation or in survey samples if the desire is to relate these characteristics to evictions.

The binary outcome model shown in Table 6 , Table 7, and Table 8 exhibited the best fit to the different combinations that were attempted in other models based on the likelihood ratio chi squares, the pseudo $\mathrm{R}$ squares, the effect parameters, and the odds ratios. This model specifies temporary state eviction bans as a function of the state's poverty rate, unemployment rate, the log of the homelessness rate, political party control in the state legislature, and governor's political party identification. In Table 6, the likelihood ratio of 41.07 with a $p$ value of .0000 indicates the model is a significantly better fit than a model with no predictors. The table also displays the coefficients of the different variables. The only significant coefficient was the indicator variable political party control of the state legislature. Being in a state where the Democrats control the legislature as opposed to Republican control increases the log odds of eviction bans by 4.05 . This relationship is statistically significant. Conversely, being in a state where the governor is a Democrat increases the log odds of eviction bans by 2.21 although this relationship is not significant. The poverty rate, unemployment rate, and log of the home lessness rate were not statistically significant.

Table 6 Logistic Regression

Logistic regression

Log likelihood $=-11.093583$

$\begin{array}{llr}\text { Number of obs } & = & 49 \\ \text { LR chi2 (5) } & = & 41.07 \\ \text { Prob > chi2 } & = & 0.0000 \\ \text { Pseudo R2 } & = & 0.6493\end{array}$

\begin{tabular}{r|rrrrrr}
\hline EB & Coef. & Std. Err. & $z$ & P $>|z|$ & [95\% Conf. Interval] \\
\hline POVP & -.1923731 & .2299594 & -0.84 & 0.403 & -.6430853 & .258339 \\
UNEMP & .0523976 & .3773683 & 0.14 & 0.890 & -.6872307 & .7920258 \\
LHLESS & .1046212 & 1.211241 & 0.09 & 0.931 & -2.269367 & 2.47861 \\
1. PCSL & 4.050037 & 1.475752 & 2.74 & 0.006 & 1.157616 & 6.942458 \\
$1 . \mathrm{GPP}$ & 2.210003 & 1.413142 & 1.56 & 0.118 & -.5597045 & 4.97971 \\
_COnS & -2.41352 & 3.831087 & -0.63 & 0.529 & -9.922314 & 5.095273 \\
\hline
\end{tabular}

Table 7 Odds Ratios

Logistic regression

Log likelihood $=-11.093583$

$\begin{array}{llr}\text { Number of obs } & = & 49 \\ \text { LR chi2 (5) } & = & 41.07 \\ \text { Prob > chi2 } & = & 0.0000 \\ \text { Pseudo R2 } & = & 0.6493\end{array}$

\begin{tabular}{r|rrrrrr}
\hline EB & Odds Ratio & Std. Err. & $z$ & P $>|z|$ & {$[95 \%$ Conf. Interval] } \\
\hline POVP & .824999 & .1897163 & -0.84 & 0.403 & .5256681 & 1.294778 \\
UNEMP & 1.053795 & .3976687 & 0.14 & 0.890 & .502967 & 2.207865 \\
LHLESS & 1.11029 & 1.344829 & 0.09 & 0.931 & .1033776 & 11.92467 \\
1. PCSL & 57.39959 & 84.70757 & 2.74 & 0.006 & 3.182337 & 1035.312 \\
1. GPP & 9.11574 & 12.88183 & 1.56 & 0.118 & .5713779 & 145.4322 \\
_COnS & .0894997 & .3428811 & -0.63 & 0.529 & .0000491 & 163.2484 \\
\hline
\end{tabular}


Table 7 displays the odds ratios for the different variables in Table 6 . Here the odds ratios for political party control of the state legislature and governor's political party are notable. If the Democrats control the state legislature, the odds for eviction bans are 57 times more likely than if the Republicans control the same body. In addition, if Democrats control the governor's office, the odds of eviction bans are 9 times more likely than if Republicans control the same office.

Table 8 displays the results of the probit regression. This table confirms the results from the logit model in Tables 6 and 7. Only political party control of the state legislature was statistically significant. The probit regression coefficients show the change in the $z$ score as a function of unit changes in the predictors. In the case of the political party control variable, having a state legislature controlled by Democrats as opposed to Republicans increases the $z$ score of eviction bans by 2.27. If the governor is a Democrat, it increases the eviction ban $z$ score by 1.24 .

Table 8 Probit Regression

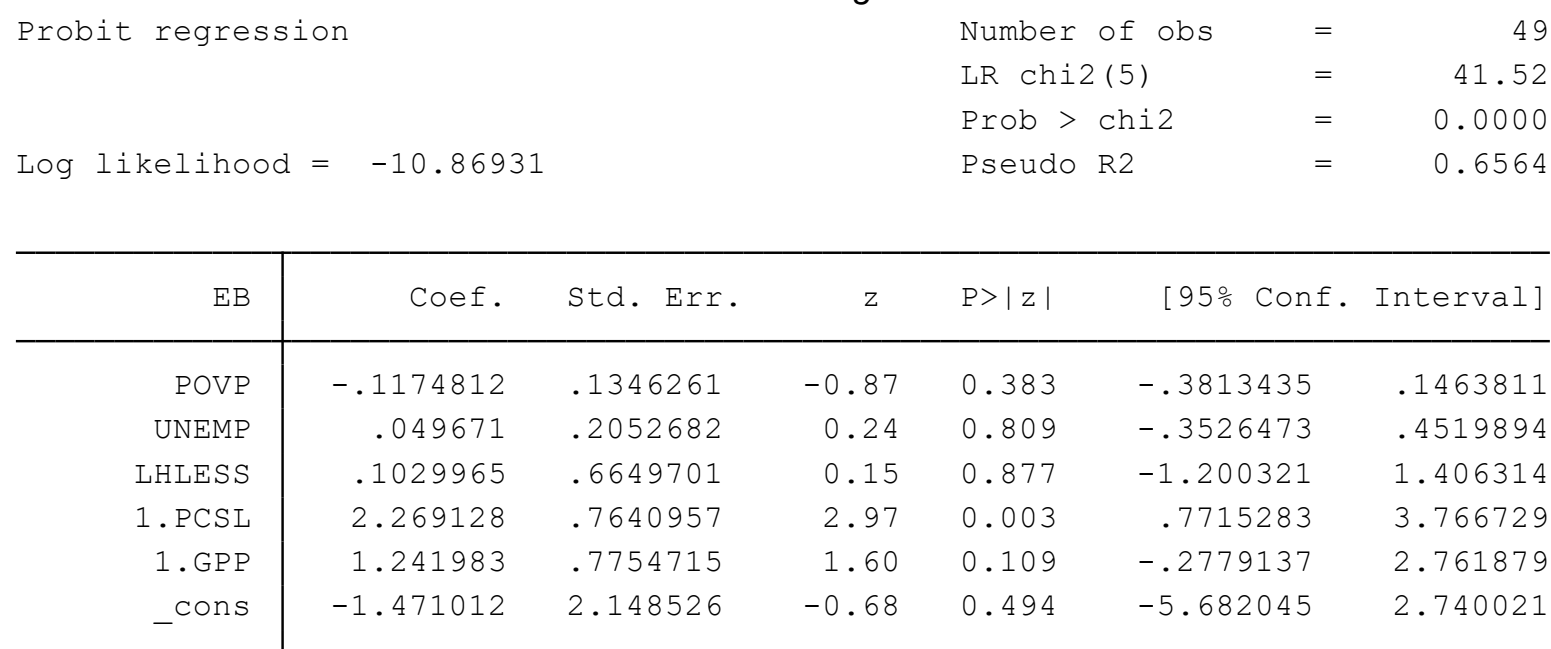

The results of the binary outcome model confirm the importance of political party control relative to temporary state eviction bans. The analysis failed to show statistical significance of the demographic variables. The tables also showed very large odds ratios and standard errors for all variables. These characteristics may be a function of the small sample size, the high intercorrelation of the predictors, and the estimation procedure. However, based on the earlier intercorrelations, the data suggests that continuing policy on renter eviction bans also needs to take into account the unemployment rate, renter households, and rent as a percentage of median family income at the state level. Detailed data at the city or local levels are needed to confirm ethnic patterns in evictions. Discussion
In the results of the logistic regression model previously described, the only significant coefficient relative to temporary state eviction bans was the political party control of the state legislature. Specifically, being in a state where Democrats control the state legislature as opposed to Republican control increases the log odds of eviction bans by 4.05 in the model. If Democrats control the state legislature, the odds of eviction bans are 57 times more likely than if Republicans control the same body. In addition, if Democrats control the governor's office, the odds of eviction bans are 9 times more likely than if Republicans control the office. The probit regression results are very similar showing political party control of the state legislature as the only significant predictor. A state's homelessness rate displayed a statistically 
significant correlation with eviction bans, but the log of the homelessness rate was not statistically significant in the regression models. Our findings suggest that at the state level Democratic elected officials have shown greater policy responsiveness to the COVID-19 public health crisis than Republicans when it comes to implementing temporary eviction bans that supplement the CDC temporary eviction ban order. In other words, partisanship has been more important than demographic variables in directing policy response to the COVID-19 pandemic at the state level. Republican state officials' lower level of adopting temporary eviction bans might support health policy research that finds the existence of a vertical partisan coalition in which state policymakers experience pressure to act as loyal party members who support their national party leaders rather than pursue pragmatic public policies that benefit public health (Thompson \& Gusmano, 2014; Thompson et al., 2018; Gusmano et al., 2020). In addition, our findings about partisanship prove interesting in light of diverging views about COVID-19 between U.S. adults who identify as Democrat or Republican. A 2020 survey conducted by the Pew Research Center found that 78 percent of Democrats and Democratic leaners believed that COVID-19 is a major threat to the health of the U.S. population, while a much smaller 52 percent of Republicans and Republican leaners believed this to be the case (Van Green \& Tyson, 2020).

\section{Conclusion}

The COVID-19 pandemic has illuminated the importance of housing as a social determinant of health, and the pandemic has resulted in a converging public health, homelessness, and joblessness crisis. The CDC's temporary eviction ban order attempts to address this crisis. In addition, many states have implemented a patchwork of temporary eviction bans as pragmatic policies to help mitigate the crisis. This paper first examined the rationale for the CDC temporary eviction ban order from a public health perspective. It then explored the relationship between political and demographic variables and the temporary eviction bans enacted in states during the COVID-19 pandemic. A statistically significant relationship between political party control of the state legislature and temporary state eviction bans served as a major finding. This result supports existing health policy research, and future research might continue to explore the role of partisanship in health policymaking.

\section{References}

[1] Alarcon, J. \& Khan, T.V. (2021). Adapting backpack medicine in COVID-19 response for people experiencing homelessness in Southern California. American Journal of Public Health, 111(1), 58-61. https://doi.org/10.2105/AJPH.2020.305956

[2] Centers for Disease Control and Prevention (2021, January 29). Order under Section 361 of the Public Health Service Act (42 U.S.C. 264) and 42 Code of Federal Regulations 70.2. https://www.cdc.gov/coronavirus/2019ncov/covid-eviction-declaration.html

[3] Centers for Disease Control and Prevention (2021b). https://covid.cdc.gov/covid-datatracker/\#cases_casesper100klast7days. Accessed April 15, 2021.

[4] Conlan, T. \& Posner, P. (2011). Inflection point? Federalism and the Obama administration. Publius: The Journal of Federalism, 41(3), 421446. doi: 10.1093/publius/pjr020

[5] Desmond, M. (2016). Evicted. Broadway Books.

[6] Desmond, M. \& Kimbro, R.T. (2015). Eviction's fallout: Housing, hardship, and health. Social Forces, 94(1), 295-324. doi: 10.1093/sf/sov044

[7] Gusmano, M., Miller, E., Nadash, P., \& Simpson, E. (2020). Partisanship in initial state responses to the COVID-19 pandemic. World Medical and Health Policy, 12(4), 380-389. doi: 10.1002/ wmh3.372

[8] Ha, Y.P., McDonald, N., Hersh, S., Fenniri, S.R., Hillier, A., \& Cannuscio, C.C. (2021). Using informational murals and handwashing stations to increase access to sanitation among people experiencing homelessness during the COVID19 pandemic. American Journal of Public Health, 111(1), 50-53.

https://doi.org/10.2105/AJPH.2020.305961

[9] Perri, M., Dosani, N., \& Hwang, S. (2020). COVID-19 and people experiencing homelessness: Challenges and mitigation strategies. Canadian Medical Association Journal, 192(26), E716 - E719. doi: 10.1503/cmaj.200834 
[10] Stewart, N. (2020, November 13). It's a time bomb: 23 die as virus hits packed homeless shelters. The New York Times.

[11] Thompson, F. \& Gusmano, M. (2014). The administrative presidency and fractious federalism: The case of Obamacare. Publius: The Journal of Federalism, 44(3), 426-450. doi: 10.1093/publius/pju011

[12] Thompson, F., Gusmano, M., \& Shinohara, S. (2018). Trump and the affordable care act: Congressional repeal efforts, executive federa- lism, and program durability. Publius: The Journal of Federalism, 48(3), 396-424. doi: 10.1093/ publius/pjy007

[13] Van Green, T. \& Tyson, A. (2020). 5 facts about partisan reactions to COVID-19 in the U.S. Pew Research Center.

https://www.pewresearch.org/facttank/2020/04/02/5-facts-about-partisan-

reactions-to-covid-19-in-the-u-s/. Accessed February 19, 2021. 